\title{
Prosthetic rehabilitation of face following naso-orbital mycosis
}

\author{
S. N. Deshpande*, S. Bhat, R. Sharma, S. Singh ${ }^{1}$, J. Fernandes \\ Departments of Plastic Surgery and ${ }^{1}$ Prosthodontics, Grant Medical College and G. T. Hospital, Mumbai, *Jaslok Hospital \\ and Research Centre, Mumbai, India
}

Address for correspondence: Sanjeev N Deshpande, A/39, Sneh-Varsha, Parsiwada, Sahar Road, Andheri (E), Mumbai - 400 099, India. E-mail: drsanjeevdeshpande@yahoo.co.in

\section{ABSTRACT}

Sino-nasal mycosis is a known complication in patients with immunological or metabolic compromise. Mainstay of treatment includes reversal of the compromised state, systemic antifungals and repeated radical debridements assisted by serial imaging. Salvage is possible provided no cerebral extension exists on presentation. The resultant deformity following debidement causes gross morbidity and psycho-social embarrassment. Surgical reconstruction is difficult on account of co-morbid diseases. Non-surgical prosthetic rehabilitation gives fairly accurate correction in these patients. We report a case of a 48 yrs. male diabetic with sino-orbital mycosis where debridement resulted in a gross morbid defect. However effective rehabilitation was achieved using three piece maxillo-facial prosthesis.

\section{KEY WORDS}

Naso-orbital mycosis, prosthetic rehabilitation, surgical debridement

\section{INTRODUCTION}

ino-nasal mycosis is a known complication in patients with immunological or metabolic compromise. Infection begins in para-nasal sinus mucosa and frequently progresses to the orbit and brain. ${ }^{[1]}$ Despite newer generation antibiotics and good intensive care, these cases are often fatal. Mainstay of treatment includes reversal of the compromised state, systemic antifungals ${ }^{[2,3]}$ and repeated radical debridements assisted by serial imaging. It is usually seen in immunocompromised states, uncontrolled diabetes, renal-hepatic failure etc. ${ }^{[4]}$ Earnest control of the comorbid disease coupled with early surgical debridement and effective antifungal therapy may salvage the patient if initiated early enough. ${ }^{[5]}$ Thus, patients who are stabilized by the above management are left with complex naso-orbital defects. Surgical reconstruction, though possible, is a risky endeavour due to co-morbid conditions. There is only a sole report in the literature of reconstruction in a patient who has recovered from sino-nasal mucormycosis. ${ }^{[6]}$

Prosthetic rehabilitation with maxillo-facial prosthesis in such a patient is a safer, inexpensive and rapid alternative with satisfactory outcome. Fixation of prosthesis could be either done with conventional methods or more recently with osseo-integrated implants. In our patient fixation of prosthesis was done with conventional method because of socio-economic reasons. 


\section{CASE REPORT}

A 48 year old male, an office clerk by profession was referred to us following maxillectomy and evisceration

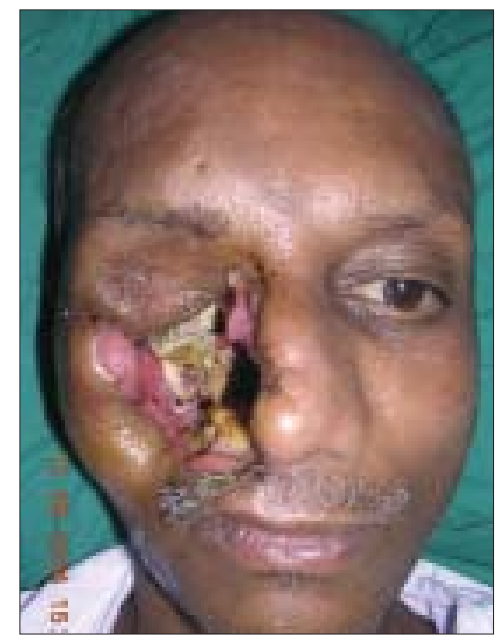

Figure 1: Facial defect following surgical debridement

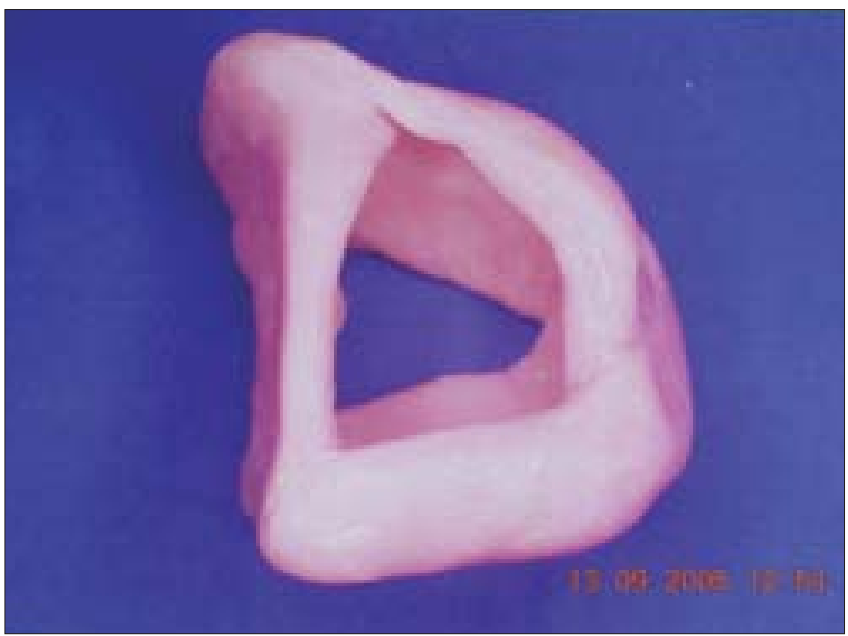

Figure 2: Maxillary obturater

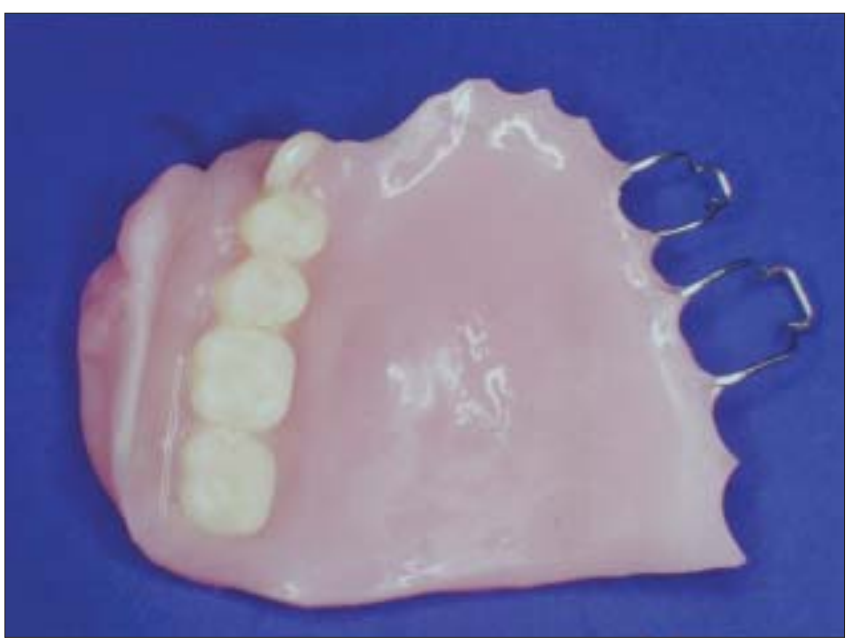

Figure 3: Partial maxillary denture of right eye at a district hospital by an ENT surgeon. Patient was a known diabetic since the last 12 years taking insulin for control of diabetes mellitus. Following an episode of diabetic ketoacidosis, he developed rapidly spreading naso-orbital mycosis and gangrene necessitating emergency maxillectomy and evisceration of an eye.

When he came to us, there was residual slough and sequestrum showing growth of Candida type fungus isolated on culture media. The patient was treated with systemic antifungal therapy (intravenous fluconozole 6 $\mathrm{mg} / \mathrm{kg}$ once daily for 2 weeks). CT scan of the face and brain did not show any intracranial involvement by the fungus. Thorough debridement of slough and sequestrum was undertaken [Figure 1] under antifungal cover and the raw areas in the orbit and maxilla were covered with split thickness skin graft. After complete healing of wounds, patient was considered for maxillo-

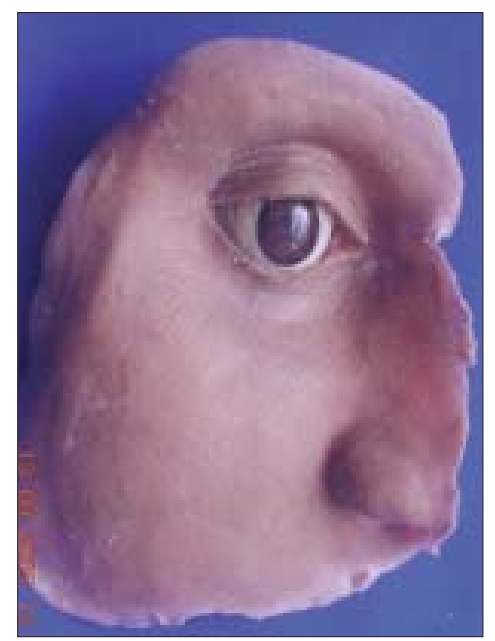

Figure 4: Superficial facial prosthesis with eye shell

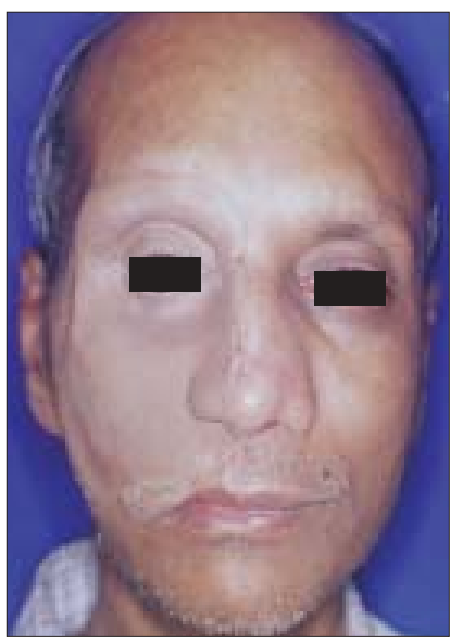

Figure 5: Final aesthetic result 
facial prosthesis.

The massive defect involving the midface and orbit made the patient socially unacceptable and he could not join his previous profession. In addition patient was also incapacitated due to constant regurgitation of food and liquid through the cheek defect and defective speech.

The various pros and cons of surgical reconstruction versus prosthetic rehabilitation were discussed with the patient and he decided to undergo maxillo-facial prosthetic rehabilitation. We involved our prosthodontic colleague for further management. A maxillo-facial prosthesis consisting of three pieces was planned for him. One was a palatal obturator with partial denture made of pink acrylic, second was an acrylic prosthesis to fill the maxilla and orbit with soft silastic covering resembling the skin of cheek, eyelid etc., and the third was an eye shell of acrylic [Figures 2-4]. Patient was educated for proper hygiene of prosthesis, its removal, cleaning and application before he went to his previous social life and the job. Figure 5 shows final result. Rehabilitation thus achieved was fast, less risky, inexpensive and to the satisfaction of the patient.

\section{DISCUSSION}

Sino-nasal mycosis is a rapidly progressive invasive fungal infection in patients with immunological or metabolic compromised conditions. ${ }^{[1]}$ Though survival in a given case has improved dramatically, number of deaths is increasing along with the rise in incidence of immunodeficiency and opportunistic infections, especially when recognition and treatment have been delayed. ${ }^{[6]}$ Such infections are uncommon in routine practice of a plastic surgeon. When one is confronted with such a case, awareness will help initiate immediate action. Necrotising fasciitis of the face has to be considered in differential diagnosis. A team approach involving the ophthalmologist, oto-rhinolaryngologist, clinical microbiologist and plastic surgeon is needed to help patient survive the disease with good result. ${ }^{[6]}$ Necrotising and progressive nature of infection along with propensity of infecting agent to invade arterioles causing an ischaemic environment necessitates multiple debridements. ${ }^{[1]}$ There is a sole report in the literature of reconstruction following mucormycosis, for orbital wall defect using vascularised galea-frontalispericranial flap.

Our patient was a middle aged diabetic who developed invasive disease during an episode of ketoacidosis. Repeated imaging and surgical debridement helped to achieve control of disease at the cost of a massive orbital and midface defect. Enormity of composite defect and co-morbid conditions posed a significant risk for major surgical reconstruction and anaesthesia. A three piece composite prosthesis provided quick and inexpensive rehabilitation with minimum risk. The maxillo-facial prosthesis met the patients functional and aesthetic needs adequately.

\section{REFERENCES}

1. Ferguson BJ. Mucormycosis of nose and paranasal sinuses. Otolaryngol Clin North Am 2000;33:349-65.

2. Cagatay AA, Oncu SS, Calangu SS, Yildirmak TT, Ozsut HH, Eraksoy $\mathrm{HH}$. Rhinocerebral mucormycosis treated with 32 grams liposomal amphotericin B and incomplete surgery. BMC Infect Dis 2001;1:22.

3. Kocak R, Tetiker T, Kocak M, Baslamisli F, Zorludemir S, Gonlusen G. Fluconozole in the treatment of three cases of mucormycosis. Eur J Clin Micorbiol Infect Dis 1995;14:559-61.

4. Bhattacharya AK, Deshpande AR, Nayak SR, Kirtane MV, Ingle MV, Vora IM. Rhinocerebral mucormycosis: An unusual presentation. J Laryngol Otol 1992;106:48-9.

5. Akoz T, Civelek B, Akan M. Rhinocerebral Mucormycosis: Report of 2 cases. Ann Plast Surg 1999;43:309-12.

6. Lari AR, Kanjoor JR, Vulvoda M, Katchy KC, Khan ZU. Orbit Reconstruction after sino-nasal mucormycosis. Br J Plast Surg 2002;55:72-5.

7. Peterson KL, Wong M. Rhinocerebral mucormycosis: Evolution of disease and treatment options. Laryngoscope 1997;107:855-62.

8. Djokic M, Bojic I, Mikic D, Ivanovic A, Drincic R, Markovic LJ, et al. Rhino-orbital Zygomycosis. Vojnosanit Pregl 2001;58:551-6.

9. Esakowitz L, Cook SD, Adams J, Doyle D, Grossart KW, Macpherson $\mathrm{P}$, et al. Rhino-orbital-cerebral mucormycosis - A clinico-pathological report of two cases. Scott Med J 1987;32:180-2.

10. Dokmatas HS, Canbay E, Yilmaz S, Elaldi N, Topalkara A, Oztoprak I, et al. Diabetic Ketoacidosis and Rhinoorbital Mucormycosis. Diabetes Res Clin Pract 2002;57:139-42.

11. Nithaynandan S, Jacob MS. Rhino-orbito-cerebral Mucormycosis. Indian J Ophthalmol 2003;51:231-6. 